\title{
Beliefs, perceptions and practices about asthma among Iranian asthma patients
}

H. Heidarnazhad ${ }^{1,2}$ and S. Tavasoli ${ }^{1}$

$$
\begin{aligned}
& \text { المعتقدات والمدر كات والمارسات حول الربو بين المصابين به في إيران } \\
& \text { حسن حيدر نزاد، ساناز توسلي }
\end{aligned}
$$

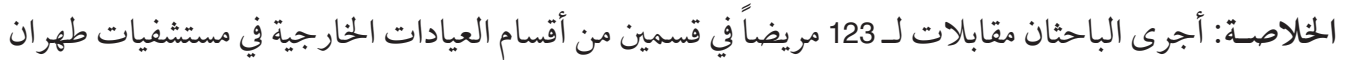

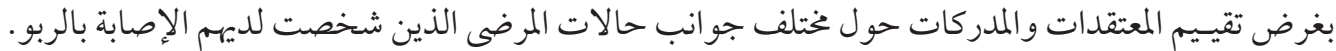

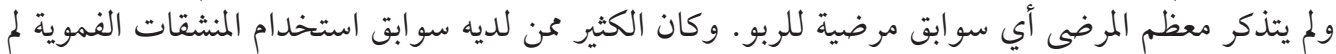

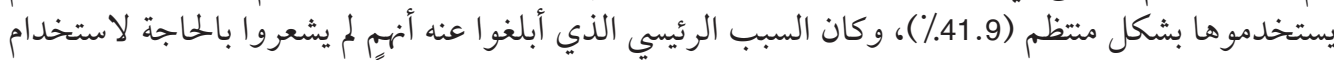

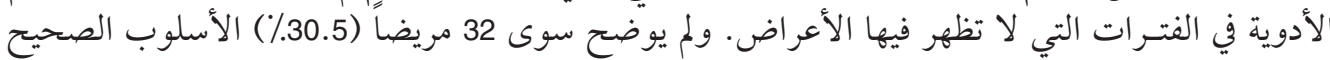

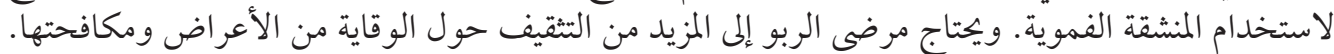

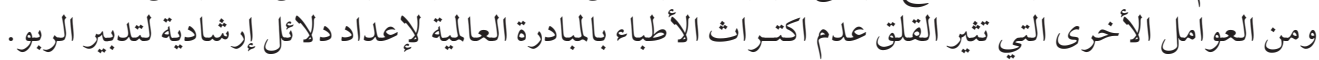

ABSTRACT To evaluate the beliefs and practices of patients diagnosed with asthma about various aspects of their condition we interviewed 123 patients attending 2 outpatient departments of hospitals in Tehran. Most of the participants did not recall their past medical history of asthma. Many patients with a history of using oral inhalers did not use these regularly $(41.9 \%)$; the major reason reported was feeling no need to use medication during symptom-free intervals. Only $32(30.5 \%)$ patients demonstrated the correct technique for using their oral inhaler. Patients with asthma need more education about prevention and control of symptoms. Neglect by physicians of the Global Initiative for Asthma management guidelines was another major concern.

Croyances, opinions et pratiques relatives à l'asthme parmi les sujets asthmatiques iraniens RÉSUMÉ Afin d'évaluer les croyances et les pratiques des asthmatiques concernant différents aspects de leur maladie, nous avons interrogé 123 patients fréquentant deux services de consultations externes d'hôpitaux de Téhéran. La plupart des participants ne se souvenaient pas de leurs antécédents d'asthme. Bon nombre de ceux qui utilisaient des inhalateurs ne le faisaient pas régulièrement $(41,9 \%)$; la principale raison invoquée était qu'ils n'éprouvaient pas le besoin de prendre des médicaments pendant les intervalles asymptomatiques. Seuls $32(30,5 \%)$ patients appliquaient la bonne technique pour utiliser leur inhalateur. Les asthmatiques doivent être mieux informés sur la prévention et la suprpession des symptômes. La non-observance par les médecins des principes directeurs en matière de prise en charge de l'asthme mis au point par l'Initiative mondiale pour l'asthme (GINA) était également très préoccupante.

\footnotetext{
'Immunology, Asthma and Allergy Research Institute, Tehran University of Medical Sciences, Tehran, Islamic Republic of Iran (Correspondence to H. Heidarnazhad: heidarnazhad@nritld.ac.ir).

${ }^{2}$ National Research Institute of Tuberculosis and Lung Disease, Shahid Beheshti University of Medical

Sciences, Tehran, Islamic Republic of Iran.

Received: 08/01/07; accepted: 28/03/07
}

المجلة الصحية لشرق المتوسط، منظمة الصحة العالمية، المجلد الخنامس عشر، العدد ع، 9 ×. ب 


\section{Introduction}

Asthma affects an estimated 300 million people worldwide, not only impinging on patients' quality of life but also accounting for approximately 1 in every 250 deaths and 15 million disability-adjusted life years lost per year [1]. In recent years the prevalence of asthma has shown a steady increase, with a corresponding increase in its social and economic impact [2].

Asthma care requires a partnership between the patient and the health care professional [2]. Successful management of asthma requires attention not only to observable behaviour but also to the underlying attitudes and beliefs which drive that behaviour [3]. It is well accepted that patients' views should be taken into account during medical decision-making, particularly in diseases such as asthma [4]. In addition, patients' beliefs about their illness play a key role in determining their adherence to treatment [5], which is an important aspect of self-management [6].

Only a few studies have attempted to investigate asthma patients' beliefs in the Islamic Republic of Iran, so the objective of this study of outpatients in Tehran was to evaluate the beliefs, perceptions and practices of asthma patients about various aspects of their condition.

\section{Methods}

\section{Study design and population}

A convenience sample of 123 patients with physician-diagnosed asthma were selected from the outpatient departments of 2 tertiary hospitals (Milad and Fayaz-Bakhsh hospitals) in Tehran, Islamic Republic of Iran from June 2005 to September 2005. All of those approached agreed to take part and were interviewed.
The inclusion criteria were age above 16 years and history of asthma and the exclusion criterion was a history of chronic respiratory diseases other than asthma. Asthma was diagnosed by a pulmonologist, according to a combination of both clinical and spirometry (reversibility to bronchodilators) criteria. Asthma severity was defined based on the Global Initiative for Asthma (GINA) guidelines [2] and patients' clinical and/or spirometry parameters.

\section{Data collection and analysis}

Data were collected via a questionnaire that was designed to examine patients' perceptions of asthma management in light of the revised asthma management guidelines published by GINA in 2004 [2]. The survey questions were not validated. Patients' demographic data, asthma severity and history, medical history, history of prescribed medication for asthma and/or other chronic diseases and smoking status were recorded. The questionnaire included both closed and open-ended questions. The second author conducted all the interviews.

The answers to open-ended questions were read several times to become familiar with the data. After highlighting the more common answers, all the data were grouped for analysis. SPSS, version 10.0.5 software was used for statistical analysis.

\section{Results}

All 123 patients were interviewed. Mean age was 46.46 (standard deviation 14.86; range 16-83) years. The demographic data of participants are shown in Table 1. About three-quarters of the patients had less than high school education, more than half had grade 1 and 2 asthma and about one-quarter were active or passive smokers. 


\begin{tabular}{|c|c|c|}
\hline Variable & No. & $\%$ \\
\hline \multicolumn{3}{|l|}{ Age (years) } \\
\hline Mean (SD) & \multicolumn{2}{|c|}{$46.46(14.86)$} \\
\hline Min-max & \multicolumn{2}{|c|}{$16-83$} \\
\hline \multicolumn{3}{|l|}{ Sex } \\
\hline Female & 73 & 59.3 \\
\hline Male & 50 & 40.7 \\
\hline \multicolumn{3}{|l|}{ Literacy/education level } \\
\hline Illiterate & 27 & 22.0 \\
\hline Low literate & 12 & 9.8 \\
\hline Elementary school & 26 & 21.1 \\
\hline Guidance school & 27 & 22.0 \\
\hline High school & 23 & 18.7 \\
\hline College & 8 & 6.5 \\
\hline \multicolumn{3}{|l|}{$\begin{array}{l}\text { Length of time with diagnosis } \\
\text { of asthma (months) }\end{array}$} \\
\hline Mean (SD) & \multicolumn{2}{|c|}{$84.42(102.13)$} \\
\hline Min-max & \multicolumn{2}{|c|}{$0-600$} \\
\hline \multicolumn{3}{|l|}{ Employment } \\
\hline Employed & 66 & 53.6 \\
\hline Unemployed $^{a}$ & 57 & 46.4 \\
\hline \multicolumn{3}{|l|}{ Immigration status } \\
\hline Immigrant & 81 & 65.9 \\
\hline Native & 34 & 27.6 \\
\hline Living in other cities & 8 & 6.5 \\
\hline \multicolumn{3}{|l|}{ Smoking status } \\
\hline Active & 7 & 5.7 \\
\hline Passive & 25 & 20.3 \\
\hline Non-smoker & 73 & 59.3 \\
\hline Ex-smoker & 18 & 14.6 \\
\hline \multicolumn{3}{|l|}{ Disease history } \\
\hline Family history of asthma & 51 & 41.5 \\
\hline $\begin{array}{l}\text { History of other chronic } \\
\text { disease }\end{array}$ & 39 & 31.7 \\
\hline $\begin{array}{l}\text { History of taking medication } \\
\text { for other chronic disease }\end{array}$ & 42 & 34.1 \\
\hline \multicolumn{3}{|l|}{ Asthma grade } \\
\hline 1 & 34 & 27.6 \\
\hline 2 & 43 & 35.0 \\
\hline 3 & 40 & 32.5 \\
\hline 4 & 6 & 4.9 \\
\hline
\end{tabular}

\section{Triggers for asthma}

Patients were asked what factors were triggers for their asthma. Most of the patients $(108,87.8 \%)$ were familiar with the concept of triggers for asthma, $7(5.7 \%)$ patients mentioned no triggers for the disease and $8(6.5 \%)$ were uncertain about the triggers. Environment, smoking and air pollution were perceived as major trigger factors. The second major trigger factor was nutritional. None of the participants mentioned drugs as an asthma trigger. The less commonly reported triggers were exercise, infection and emotional and occupation factors. Despite knowledge of active and passive smoking as triggers of asthma, 7 (5.7\%) patients were active smokers and 25 (20.3\%) were exposed as passive smokers.

\section{Physician visits and medication use}

A majority of patients $(74,60.1 \%)$ had only partial or no recall about their last visit to a physician. Of 97 patients who recalled their last physician visit completely or partially, $16(16.5 \%)$ had made at least 1 visit to a general practitioner (GP) for their asthma.

A number of patients had no recall (19, $15.4 \%)$ or only partial recall $(73,59.3 \%)$ of their history of medication use (Table 2). There was no relation between asthma grade and recollection of past medication history among patients who had a history of medication use $(P=0.205)$. The most frequently reported medications were various types of metered dose inhaler (MDI), theophylline, antibiotics, antihistamines and expectorants.

\section{Using metered dose inhaler drugs}

Some patients $(18,14.6 \%)$ had not been prescribed any kind of oral inhaled mediciation. Of these, 11 were new cases of asthma who had made no previous visits to a physician, but the other 7 had had the diagnosis 


\begin{tabular}{|c|c|c|c|c|c|c|c|c|}
\hline \multirow{3}{*}{$\begin{array}{l}\text { Asthma } \\
\text { grade }\end{array}$} & \multicolumn{8}{|c|}{ Recall of medication use } \\
\hline & \multicolumn{2}{|c|}{ No recall } & \multicolumn{2}{|c|}{ Partial recall } & \multicolumn{2}{|c|}{$\begin{array}{l}\text { Complete } \\
\text { recall }\end{array}$} & \multicolumn{2}{|c|}{$\begin{array}{l}\text { No medication } \\
\text { history }\end{array}$} \\
\hline & No. & $\%$ & No. & $\%$ & No. & $\%$ & No. & $\%$ \\
\hline 1 & 1 & 0.8 & 19 & 15.4 & 8 & 6.5 & 6 & 4.9 \\
\hline 2 & 9 & 7.3 & 23 & 18.7 & 7 & 5.7 & 4 & 3.3 \\
\hline 3 & 8 & 6.5 & 28 & 22.8 & 4 & 3.3 & 0 & 0.0 \\
\hline 4 & 1 & 0.8 & 3 & 2.4 & 2 & 1.6 & 0 & 0.0 \\
\hline Total & 19 & 15.4 & 73 & 59.3 & 21 & 17.1 & 10 & 8.2 \\
\hline
\end{tabular}

of asthma for a while. These 7 patients had asthma grade 2 or more. The 105 remaining ptients who had a history of using oral inhalers were asked if they were prescribed oral inhalers at every consultation for asthma: 15 of them (14.3\%) did not remember, 26 $(24.8 \%)$ did not have an inhaler prescription at every visit and 64 of $(60.9 \%)$ were always prescribed oral inhalers.

Of 105 patients using oral inhalers, 44 $(41.9 \%)$ did not take their medication as prescribed. Feeling that there was no need for medication during symptom-free intervals was the most commonly given reason for non-compliance. Drug side-effects were the second reason. Other reasons were fear of dependency and pessimistic beliefs about medicines.

After these questions, the patients were asked to show and explain how they used their metered doses inhalers. Only $32(30.5 \%)$ patients used their oral inhaler correctly; 73 had some problems in using their inhaler.

\section{Managing asthma attacks}

Half of the patients $(62,50.4 \%)$ reported that they did not suffer from asthma attacks; 30 of these had grade 3 or 4 asthma (Table 3). The remaining 61 patients were asked about how they managed their asthma attacks. Most of them $(60,98.4 \%)$ were familiar with using the "blue spray" (salbutamol inhaler) at the time of attack but they also used other treatment methods (51, $83.6 \%$ ); for example making an emergency hospital visit, getting in a comfortable position and breathing fresh air. One patient did not use any treatment at the time of asthma attacks.

\begin{tabular}{|c|c|c|c|c|c|c|c|c|}
\hline \multirow{3}{*}{$\begin{array}{l}\text { Asthma } \\
\text { grade }\end{array}$} & \multicolumn{4}{|c|}{ Ever had asthma attack } & \multicolumn{4}{|c|}{ Had asthma attack in previous year } \\
\hline & \multicolumn{2}{|c|}{ Yes } & \multicolumn{2}{|c|}{ No } & \multicolumn{2}{|c|}{ Yes } & \multicolumn{2}{|c|}{ No } \\
\hline & No. & $\%$ & No. & $\%$ & No. & $\%$ & No. & $\%$ \\
\hline 1 & 10 & 29.4 & 24 & 70.6 & 3 & 8.8 & 31 & 91.2 \\
\hline 2 & 21 & 48.8 & 22 & 51.2 & 11 & 25.6 & 32 & 74.4 \\
\hline 3 & 27 & 67.5 & 13 & 32.5 & 23 & 57.5 & 17 & 42.5 \\
\hline 4 & 3 & 50.0 & 3 & 50.0 & 3 & 50.0 & 3 & 50.0 \\
\hline Total & 61 & 49.6 & 62 & 50.4 & 40 & 32.5 & 83 & 67.5 \\
\hline
\end{tabular}

المجلة الصحية لشرق المتوسط، منظمة الصحة العالمية، المجلد الخنامس عشر، العدد ع، 9 +. 


\section{Exercise}

Almost half the patients $(58,47.2 \%)$ believed that exercise affected their asthma; 42 (34.1\%) believed that exercise improved their asthma and $16(13.0 \%)$ that it exacerbated their disease. Among those who believed that exercise improved their condition, 24 took regular exercise and $18 \mathrm{did}$ not, and among the patients who reported exacerbation of asthma after exercise, 3 took regular exercise and 13 did not. A total of 44 patients $(35.8 \%)$ took regular exercise.

\section{Nutrition}

A majority of participants $(93,75.6 \%)$ reported food-induced asthma. Nuts (55, $44.7 \%)$, fried foods $(41,33.3 \%)$ and sweets $(37,30.1 \%)$ were the most frequently reported by participants as asthma triggers. Many participants $(75,61.0 \%)$ reported overeating as an asthma trigger. Only 18 patients (14.6\%) reported feeling better by consuming some kind of food.

Dietary advice had been offered to 66 (53.7\%) participants. Of these, 52 had tried to modify their diet as advised, while 56 had modified their diets independent of dietary advice. Physicians were the most common source of dietary advice $(61,92.4 \%)$. Other sources were patients' family and relatives.

\section{Learning about asthma}

All the participants were asked about what effect having more knowledge about asthma would make to their condition. A majority $(76,61.8 \%)$ agreed that learning about asthma would improve their condition, 10 $(8.1 \%)$ believed it would not have any effect and $37(30.1 \%)$ believed that having better knowledge and learning would have a partial effect. Only 19 (15.4\%) participants, however, had tried to learn more about their condition.

\section{Alternative medicine}

A total of 74 patients $(60.2 \%)$ had been advised to use herbal medicines and 58 $(47.2 \%)$ had used them. Of these patients 28 (48.2\%) mentioned beneficial effects after use. The most common advised drugs were: pennyroyal (Mentha pulegium), borage (Echium amoenum), quince seed (Cydonia oblonga), basil seed (Ocimum basilicum), flixweed (Descurainia sophin), plantain seed (Plantago major), linseed (Linum usitatissium) and thyme (Thymus vulgaris), although 32 participants did not know the names of the herbal medicines. Pennyroyal and thyme were most frequently reported as effective (by $17.6 \%$ and $16.2 \%$ of users respectively).

Most of the participants $(91,74.0 \%)$ had not used any vitamin or mineral supplements. All of the participants were asked about the effect of supplements on their condition; $102(82.9 \%)$ did not have any ideas about the subject, $13(10.6 \%)$ believed that supplements had no effect on their disease and only 8 patients (6.5\%) believed that supplements improved their condition.

\section{Discussion}

Because patients' beliefs and practices play a role in understanding, defining and responding to illness, it is important to understand that such beliefs may vary between ethnic groups. Patients often use alternative medicines and practices alongside conventional medical ones, and clinicians should be aware of these in order to optimize health education and clinical management [7].

In spite of knowledge about active and passive smoking as triggers of asthma, $5.7 \%$ of our patients were active smokers and $20.3 \%$ passive smokers. An active antismoking education campaign is a useful tool for preventing exacerbation of asthma 
$[2,8]$. Due to the important role of air pollution in the control and exacerbation of asthma [9] and the high air pollution in Tehran and other large cities of the Islamic Republic of Iran, control of this problem is a major factor in control of asthma or exacerbation of asthma attacks.

Asthma is a chronic disease and patients need regular supervision, monitoring and support by health care professionals who are well-informed about asthma [2]. According to Hertzman et al. [10], all health carers at the primary care (nurses and GPs) and higher stages of the health care system should be involved in the care of asthma patients. It has been shown that the participation of GPs in managing asthma leads to better asthma control and improved asthma care [11]. Unfortunately only a minority of our patients made regular GP visits and the rest of the patients were treated randomly by various physicians. This can be an important factor in frequent exacerbations of asthma and ever higher mortality due to uncontrolled asthma [11]. We suggest that an asthma control management plan should be integrated into health system programmes similar to those for chronic diseases such as tuberculosis [12].

Educating patients to improve their selfmanagement skills is the cornerstone of good asthma care $[13,14]$. In our study, there was no difference in recall of past medication history between different asthma grades and most of the patients only partially remembered their past medication history. In addition, only about one-third of the patients had the correct technique for using their MDI drugs. Thus it seems that all asthma patients, regardless of their asthma severity, need more education to improve their self-management skills. The patients' negative beliefs about MDI drugs must also be considered a major part in their education as $35.7 \%$ of our patients were irregular users of MDI drugs due to these beliefs.

The medicines most frequently prescribed to our patients were theophylline, antibiotics, antihistamines and expectorants. This differs from GINA guidelines: theophylline is not the first-line drug for asthma and has side-effects and the others have no place in asthma management [2]. In addition, although MDI drugs are the best medication for asthma management [2], 26 participants did not have a regular prescription for MDI drugs and 7 patients with grade 2 or greater asthma were not prescribed any MDI drugs from the beginning of their diagnosis.

Educational programmes should also target physicians. A study in 2004 reported the lack of universal definitions among physicians, especially between GPs and specialists, regarding essential notions of asthma care, such as promoting asthma control or avoiding exacerbation [15].

With increasing asthma grade, there was an increase in the rate of patients who suffered attacks. Around half the grade 3 and 4 asthma patients were uncontrolled. This poor control of severe asthma among our patients requires that more attention be paid to management of these patients.

It was believed by $13.0 \%$ of the patients that exercise exacerbated their disease. Although exercise has been reported to be a trigger, it has been shown that short episodes of exercise may be beneficial for people with asthma [16]. Even professional athletes with asthma can exercise regularly, with accurate diagnosis and classification and appropriate preventive measures and pharmacological intervention; thus it is possible for athletes to participate in the sport of their choice in nearly all situations [17].

A majority of patients reported food-induced asthma. Since existing data about the effect of food and nutrients on asthma are

المجلة الصحية لشرق المتوسط، منظمة الصحة العالمية، المجلد الخنامس عشر، العدد ع، 9 +. 
controversial [18], more detailed and interventional studies are needed to evaluate this kind of association with precise measuring of food and nutrient intake and asthma status to ascertain whether any modifications of food intake could be beneficial in the prevention or amelioration of asthma.

A high proportion of patients had been advised to take herbal medicine. There are some studies evaluating the effect of herbal medicine in asthma, but there is a general lack of scientific data to support the use of these herbs in asthma [19]. As half of our patients using herbal medicine reported relief from symptoms, it emphasizes the need for evaluation of these therapies in proper controlled trials.

Few patients had used vitamin or mineral supplements. There is some epidemiological evidence about the effect of vitamins and minerals in asthma, but the results of controlled trials are controversial [19-21], so more controlled trials are needed to evaluate the effect of supplements in asthma.

We are aware that our study has some limitations. All of the participants were chosen from 2 outpatient clinics of tertiary hospitals, where most of the subjects had low socioeconomic status. Furthermore, all of the interviews were conducted by the first author of the study. This might result in a bias by leading the patients to certain answers. For future research, to reduce the sample bias, more community-based investigations should be undertaken to represent the full spectrum of people with asthma.
In addition, more standardized questionnaires should be used to assess patients' knowledge, attitude and behaviour in order to assess the relation between these data and asthma control.

Improvement of the quality of care in asthma requires a comprehensive knowledge of patients and the management of their asthma. It has been suggested that patients are relatively unaware that most of their asthma-related problems are due to inadequate control, and that more appropriate behaviour toward asthma control therapy could improve this situation [15]. Therefore, it had been suggested that better patient education is necessary in order to improve the management of asthma. Previous studies have reported that better knowledge of the disease by patients improved adherence to treatment and changed their perception of the disease [22]. In addition, when patients were better educated about their disease they were less likely to experience asthma-related adverse events. Education should stress the importance of regular use of asthma control medications. Explanation and demonstration of how to use inhaler devices should not be overlooked [15].

\section{Acknowledgements}

We would like to thank the patients and personnel of the outpatient clinics of Milad and Fayaz-Bakhsh Hospitals for their kind cooperation.

\section{References}

1. Masoli M et al. Global burden of asthma. Bethesda, Maryland, Global Initiative for Asthma, 2004.

2. Pocket guide for asthma management and prevention. Bethesda, Maryland, Global Initiative for Asthma, 2006.
3. Hussein S, Partridge M. Perception of asthma in south Asians and their view on educational materials and self-management plans: a qualitative study. $\mathrm{Pa}$ tient education and counseling, 2002, 48(2):189-94. 
4. Hyland ME, Stahl E. Asthma treatment needs: a comparison of patients' and health care professionals' perceptions. Clinical therapeutics, 2004, 26(12):214152.

5. Horne R, Weinman J. Patient's beliefs about prescribed medicines and their role in adherence to treatment in chronic physical illness. Journal of psychosomatic research, 1999, 47(6):555-67.

6. Van Es SM et al. Predicting adherence to prophylactic medication in adolescents with asthma: an application of the ASE model. Patient education and counseling, 2002, 47(2):165-71.

7. Patcher LM et al. Variation in asthma beliefs and practices among mainland Puerto Ricans, Mexican Americans, Mexicans, and Guatemalans. Journal of asthma, 2002, 39(2):119-34.

8. Thomson NC, Chaudhuri R, Livingston E. Asthma and cigarette smoking. European respiratory journal, 2004, 24:822-33.

9. Suzuki D. Expanding the health care debate. Canadian medical association journal, 2002, 166(13):1678-9.

10. Hertzman PA, Kelly HW, Coultas D. Chronic illness care in Russia: a pilot project to improve asthma care in a "closed city". Chest, 2005, 127(3):861-5.

11. Zwar NA et al. General practitioner views on barriers and facilitators to implementation of the Asthma 3+ Visit Plan. Medical journal of Australia, 2005, 183(2):64-7.

12. Barker J, Makatini Z, Millard J. Tuberculosis and health sector reform: experience of integrating tuberculosis services into the district health system. International journal of tuberculosis and lung disease, 2000, 4(5):486.

13. Perneger TV et al. Effect of patient education on self-management skills and health status in patients with asthma: a randomized trial. American journal of medicine, 2002, 113(1):7-14.

14. George MR et al. A comprehensive educational program improves clinical outcome measures in inner-city patients with asthma. Archives of internal medicine, 1999, 159(15):1710-6.

15. Demoly $P$ et al. Control and exacerbation of asthma: a survey of more than 3000 French physicians. Allergy, 2004, 59:920-6.

16. Kilpeläinen $\mathrm{M}$ et al. Body mass index and physical activity in relation to asthma and atopic diseases in young adults. Respiratory medicine, 2006, 100(9):1518-25.

17. Allen TW. Return to play following exercise-induced bronchoconstriction. Clinical journal of sport medicine, 2005, 15(6):421-5.

18. Woods RK et al. Food and nutrient intakes and asthma risk in young adults. American journal of clinical nutrition, 2003 78(3):414-21.

19. Fogarty $A$ et al. Oral magnesium and vitamin C supplements in asthma: a parallel group randomized placebo-controlled trial. Clinical and experimental allergy 2003, 33(10):1355-9.

20. Zalewskia PD et al. Zinc metabolism in airway epithelium and airway inflammation: basic mechanisms and clinical targets. A review. Pharmacology and therapeutics, 2005, 105(2):127-49.

21. Pearson PJK et al. Vitamin E supplements in asthma: a parallel group randomized placebo controlled trial. Thorax, 2004, 59(8):652-6.

22 Kaplan $\mathrm{M}$ et al. Use of herbal preparations in the treatment of oxidant-mediated inflammatory disorders. Complementary therapies in medicine, 2007, 15:207-16. 